\title{
Anatole France y la América Latina
}

\begin{abstract}
A NATOLE France anti-nacionalista e internacionalista; A Anatole France apóstol de la humanidad sin distinción de razas, de nacionalidades ni de religiones: he aquí el aspecto más conocido de su genio. (1) Pero hay otro Anatole France, en contradicción evidente con el primero (para los literatos, la contradicción no importa). Es el France apóstol del mundo latino, que tituló uno de sus libros Le Génie latin. La expresión "mundo latino" encubre ideologías opuestas: para algunos, significa catolicismo conservador, jerarquía tradicional; para otros -y entre éstos hay que contar a Anatole France-significa buen gusto, paganismo, derecho romano, escepticismo, racionalismo. Para éstos, el cristianismo no es más que una deformación del genio latino, impuesta por los judíos. Hay otro problema. ¿Qué representa, dentro del mundo latino, la América llamada "latina"? Para algunos es una degeneración, y para otros, un nuevo florecimiento del mundo latino. ¿Qué pensaba Anatole France de este problema delicado y difícil? Nuestros informes sobre esta materia resultan del viaje que él hizo en Sudamérica en 1909. Desgraciadamente, los documentos que nos quedan son contradictorios.

La noticia más completa que tenemos del viaje de France al Nuevo Mundo se encuentra en Jean-Jacques Brousson, Itinéraire de Paris a Buenos Ayres (Paris: Cres, 1928). Este libro - anecdótico y de débil construcción- es compañero de ese otro tan conocido, que tuvo un "éxito de escándalo": Anatole' France en pantoufles, retrato nada respetuoso de un
\end{abstract}


viejo cínico cuya única pasión era el erotismo. El secretario del maestro nos cuenta (p.60), que France fué invitado a dar en el año 1909 una serie de diez conferencias en Buenos Aires por el Conservatorio de esa capital. Los honorarios serían de 80,000 francos. Se le dejaba completa libertad en cuanto al tema de las conferencias. France acababa de publicar su voluminosa obra sobre Juana de Arco, fruto de veinte años de trabajo, y para cambiar de atmósfera, quería emprender una obra sobre Rabelais. El cura de Meudon sería pues el objeto de sus conferencias. A France lo acompañaría su secretario, Brousson, quien dictaria, en la Universidad de Buenos Aires, una serie de doce conferencias sobre cualquier tema, por las cuales recibiría 12,000 francos. El maestro no quería aceptar la oferta. Su protectora, Mme. de Caillavet, no quería sufrir la separación. Además, France, desencantado ya de todo, lo menospreciaba todo, y miraba con desdén al Nuevo Mundo:

"Ce sont des enfants, ces Argentins. Au poids de l'or, ils embarquent nos grands hommes. Ils les veulent mesurer, misérables et dépaysés, comme nous allons béer, au jardin (sic) des Plantes, devant la cage de la girafe ou de l'onagre" (p. 64).

Pero al fin aceptó. Al saber Mme. Caillavet el proyecto de viaje, vino a la Villa Saïd e hizo una escena. Quería a la fuerza acompañar a France; proclamaba que no podía haber para ello dificultad alguna, ya que su liaison era cosa pública y aceptada. El maestro, cuya única razón al emprender el viaje era libertarse de su amante, replicó que su idea era imposible, ya que a los argentinos y a los brasileños, buenos católicos, les chocaría tal manifestación de inmoralidad, y como pasaba por el período más agudo de su anticlericalismo, añadió, con la violencia que le presta siempre Brousson: "Ce sont des brutes! Ce sont des sauvages! Ils s'en tiennent au catéchisme" (p. 77).

La Caillavet no se dejó persuadir, y tuvo una crisis de nervios. Cuando el viejo verde recibió a los representantes de la prensa, dió como motivo de su viaje en primer lugar su curiosidad de conocer a la América latina y su admiración por las argentinas, las más bellas mujeres que había visto. 
Se embarcó en Cherbourg con Brousson, a bordo del vapor inglés Amazon, de la Royal Mail Line. La separación de la Caillavet provocó una escena bastante congojosa. Para acompañar a France en su viaje, envió ella a un criado suyo, François, que tenía como misión secreta darle a ella noticias exactas sobre los hechos y milagros del viejo galán y poco fiel. A bordo había también una tropa de la Comédie Française, en cuya compañía pasó France la mayor parte del viaje. No olvidemos al mediocre pintor "V..." que se había especializado en cuadros de A. France y de la Villa Saïd y que, abusando siempre de la generosidad del maestro, hacía el mismo viaje que él con el objeto de vender sus telas. En Lisboa, los izquierdistas portugueses le dieron a France una entusiasta recepción, ofreciéndole un banquete demasiado académico para el inmortal amoral. En Madera, France visitó los puntos obligatorios del turismo, pero no manifestó entusiasmo alguno, ni hizo el menor esfuerzo de comprensión. El vapor hizo escala en Pernambuco, donde France vió por vez primera el Nuevo Mundo, a la América hispana. La colonia francesa de Pernambuco le mandó al maestro parisiense un telegrama de felicitaciones y un cesto de frutas exóticas, que él no pudo o no quiso comer. En Bahia, hubo recepción oficial y más ambiente tropical; las dos cosas dejaron indiferente al viejo verde. Todos los viajeros se entusiasmaron por la bahía de Río de Janeiro; France no manifestó ninguna emoción. Vino a saludarle a bordo una delegación de brasileños. France, cuyo interés lo monopolizaba cierta actriz rolliza madura, fingió una enfermedad grave y no quiso recibir a la delegación. Pero tuvo que someterse a la recepción que le hizo la Academia de la capital brasileña. En su discurso, el presidente del augusto cuerpo alabó el estilo de France, pero censuró la inmoralidad de sus escritos. El maestro, hipócrita incomparable, le echó flores a cada quisque. Terminó con un panegírico del Brasil: "O Brésiliens! Soyez fiers de votre jeunesse, comme nous le sommes de notre veillesse". Auguró para la república neo-portuguesa un porvenir brillante: "C'est á Rio que s'est refugié Pallas-Athéné" (p. 197). En la biblioteca, France hizo algunas alusiones irónicas a los insectos que se comían los hermosos volúmenes. En el palacio im- 
perial, ahora presidencial, donde hubo banquete, admiró France cierta pintura del ex-emperador, artista y mecenas; no llegó a comprender por qué lo habían destronado. Los brasileños reprochaban a France que fuera a dictar sus conferencias en la Argentina; los argentinos, afirmaban, son unos salvajes. En Montevideo, el maestro no fué a tierra; a los muchos que vinieron a bordo a saludarle, les hizo un discurso lleno de la hipocresía de siempre, afirmando la admiración y el afecto que les tenía a los montevidenses.

Cierto juez de Buenos Aires puso su casa a la disposición del maestro. Escribióle un grupo de socialistas militantes, diciendo que dicho juez era un horrible cavernícola, y que el maestro estaba en la obligación moral de rechazar su invitación. El epicúreo, socialista diletante, no hizo caso, pretendiendo que iba a la Argentina a dictar conferencias literarias, y no políticas. En la metrópolis argentina, France se instaló en el espléndido palacio del juez, quien le mostró vanidosamente a su huésped los tesoros artísticos que encerraba. Brutalmente, uno tras otro, France afirmó que eran espurios, es decir que el juez y su padre eran unos ricachones simples. Cuando dió France su primera, conferencia, apenas una' sola dama vino a escucharle, ya que el arzobispo lo había anatematizado; acusaba al maestro de querer difundir el ateísmo en el Nuevo Mundo. En el palacio del juez France instaló a la actriz que lo había acaparado en el viaje. Allí se comportó ella como si fuese la dueña de la casa, e invitó a comer allá a toda la compañía! Al juez, que tenía fama de homosexual, se le crisparon los nervios al ver en su casa a tantas mujeres de modales poco finos, por no decir nada de los hombres. Recibía el maestro un diluvio de correspondencia; contestaba Brousson obligado a falsificar su escritura. Los museos argentinos le parecían al francés tan espurios como la colección artística del juez. La arquitectura de este país sin piedra no era para él sino una monstruosidad de origen internacional. ¿Los indios? Unos salvajes que no merecían su atención. Mientras tanto, las conferencias del maestro iban hacia un fracaso económico, y la prensa le hacía una crítica bastante agria, a tal punto que Brousson no se atrevió a dar sus conferencias en la Universidad. Otro desastre: llegó a Buenos Aires Blas- 
co Ibáñez, quien, con su elocuencia populachera, provocó un entusiasmo delirante. Mientras que el francés daba una serie de conferencias serias sobre Rabelais, el español hablaba sobre una increíble variedad de asuntos. El banquete que ofreció el Jockey-Club al maestro fracasó por dos razones: no había mujeres, $\mathrm{y}$ el huésped de honor se vió en la obligación de llevar frac, cosa que le ponía siempre de malísimo humor. Llegó la hora de embarcarse para Europa. Al pobre Brousson France le dejó en el mismísimo muelle, con un billete de vuelta para otro vapor, nada más. Afortunadamente, Enrique Larreta, autor de La gloria de Don Ramiro, que iba a Francia, vino al socorro del pobre secretario. France llegó a París con su actriz, provocando un escándalo general y un acceso de furor de Mme. Caillavet. La comediante reinó cierto tiempo en la Villa Saïd, pero France se cansó de ella, y volvió con profunda satisfacción a su antigua protectora. Fueron los dos a la casa de campo de los Caillavet en Capian, que estaba a poca distancia de Burdeos. En esta ciudad encontraron por casualidad a Brousson, con su familia argentina. La Cailla. vet quiso hacer la paz con el secretario, pero éste no pudo olvidar lo que le había hecho el literato irresponsable. Poco después murió la mujer que había llevado a France a la celebridad.

La calumnia de Brousson no quedó sin contestación. En el Mercure de France de junio 1, 1929 (pp. 550-578), apareció un artículo titulado "Anatole France et le voyage en Argentine". El autor era Pierre Calmettes, el pintor de quien Brousson había hecho una breve alusión, el artista mediocre e interesado que quería aprovecharse del viaje de France para vender sus telas en la Argentina. Calmettes al contrario habla como si hubiese sido un íntimo del maestro durante el viaje, casi con el mismo título que Brousson. Había evidentemente una rivalidad sorda entre los dos. En su artículo, Calmettes analiza la narración de Brousson incidente por incidente, con el objeto de probar que constituye una falsificación total de la realidad, una falsificación ingeniosa y sobre todo maliciosa. Calmettes cuenta que el conservatorio Labarden envió como embajadores a la gran actriz Mme. Moreno y al secretario de dicha organización, el poeta Juan Pablo Echagüe, para per- 
suadir a France a que fuese a Buenos Aires donde daría en el Teatro Odeón, durante el mes de junio 1909, una serie de conferencias. La parte técnica de la expedición fué encargada a un especialista parisiense, M. A. Cahen. Anatole France animó a Calmettes a acompañarle en el viaje, pero Brousson se hizo invitar gracias a una doble mentira, contando a los organizadores que el maestro insistía en que su secretario le acompañase, y al maestro que el Conservatorio le había invitadó a dar en Buenos Aires una serie de conferencias sobre Jean-Jacques Rousseau. La actriz a quien se lió France se llamaba Jeanne Brindeau; Calmettes habla siempre de ella con mucho respeto. Otro objeto de la ironía de Brousson, el juez Lavallol, que vivía en el hermoso palacio de la Calle Andes de Buenos Aires, merece, según Calmettes, una mención cortés y apreciativa. El año siguiente (1910), Calmettes hizo otro viaje a la Argentina. France le encargó que le llevase a su huésped una valiosa colección de dibujos de gran mérito artístico, y una afectuosa carta que, fuera de lo personal, contenía frases muy halagadoras de recuerdo para Buenos Aires y los argentinos. (2) La ruptura entre France y Brousson tuvo lugar en Buenos Aires días antes de embarcarse aquél; la escena en el muelle contada por Brousson es pura invención. Para el viaje de vuelta — con estancias en Montevideo, São Paulo y Río de Janeiro, donde dió conferencias sobre Augusto Comte y Pierre Laffitte- Anatole France llevó consigo como secretario a Calmettes. Un vapor de la Compañia Mihanovich, el Viena, los llevó a Montevideo, donde bajaron en el Hotel Lanata. El vapor Oropesa los llevó después a Río, y de allí a Cherbourg, el Danube de la Royal Mail Line. Al llegar a París, France rompió inmediatamente con Mlle. Brindeau; ni siquiera bajaron juntos del tren. De manera que la historia de Brousson acerca del drama triangular es invención pura, es decir, una mentira indecente.

¿Quién nos cuenta la verdad, Brousson o Calmettes? Brousson exagera sin duda y, puede decirse, falsifica ciertos episodios. Pero su retrato de A. France es más humano, más íntimo que la estatua oficial de Calmettes. Seguramente conocía mejor al maestro. Calmettes - que habla concienzuda- 
mente y con detalles precisos-da sin embargo la impresión de decir : ¡Yo también conocí al maestro! France había muerto en 1924. Y, cosa importante, la crítica de Calmettes cambia muy poco lo que dijo Brousson sobre la actitud íntima de France hacia la América Latina.

El volumen XVII de las Oeuvres completes de France (Paris: Calmann-Lévy, 1928) contiene el texto de las conferencias que dió France en el Nuevo Mundo. El curso sobre Rabelais ocupa las páginas 1-265. Es extraño que el carácter erudito de estas conferencias haya espantado a la gente, ya que no es más que "un cours élémentaire sur Rabelais", como confiesa France en la dedicatoria. Es sobre todo un resumen muy ameno de la gran obra de Rabelais y también de su vida. Inició las conferencias con un saludo al genio latino de la Argentina :

"Je veux tout d'abord vous exprimer ma reconnaissance, ma joie et ma fierté de l'accueil que j'ai reçu dans votre belle patrie. Les témoignages de votre faveur que vous m'avez tant prodigués dès ma venue parmi vous, je les reçois, je les accepte, parce que je ne les rapporte pas à moi qui ne suis rien, mais à ce que je représente: ce que vous avez accueilli en moi, c'est l'esprit français, frère du vôtre, c'est une langue, une littérature et des traditions, qui durant tant de siècles, dans notre vieille Europe, ma mère et la vôtre, ont été unies, associées, mêlées à votre langue, à votre littérature, à vos traditions, c'est le génie latin, c'est l'union intellectuelle des enfants de Molière et des héritiers de Cervantès. Frères et amis latins qui, après avoir, par vos ancêtres, accompli tant de grandes et belles oeuvres en Europe, fondez aujourd-hui, en ce nouveau monde, si vaste et si fécond, la civilisation de l'avenir, recevez le salut d'un homme ému et joyeux de votre jeune grandeur. Vous unissez, dans vos moeurs nobles et charmantes, à l'activité de l'esprit moderne et à la douceur des temps nouveaux, la générosité de vos grands ancêtres et la vieille fierté castillane; je salue en vous un grand passé et un grand avenir".

Sabemos que France escogió el tema de Rabelais para cambiar de ambiente después de veinte años de trabajo sobre 
Juana de Arco. Pero la razón no es suficiente, ya que France se vió en la obligación de declarar que no heriría ninguna sensibilidad en sus conferencias; omitió, pues, todo lo que en Rabelais podría ofender las ideas morales o religiosas de los argentinos. France, que había escrito tantas páginas poco edificantes, omitió por completo la crudeza de Rabelais. El suyo parece un Rabelais para señoritas. Pero es siempre Rabelais, padre de los libertinos franceses, y la diplomacia de France consistió en "introducir" su nombre en la sociedad bonaerense.

Asistió a una de las conferencias Blasco Ibáñez. France le saludó con palabras llenas de falsa modestia, de elogios huecos que indican un fondo de hipocresía en el maestro.

En Montevideo y en São Paulo dictó France una conferencia sobre Pierre Laffitte, el sucesor de Comte como jefe del positivismo, y sobre Comte mismo, dictó otra en Río de Janeiro. Sabemos que France compuso estas dos conferencias en Montevideo, ya que el manuscrito, que pertenece a M. Jules Couêt, está compuesto de hojas provenientes del "Gran Hotel Lanata Hnos." Estas conferencias se encuentran en el mismo Tomo XVII de las obras completas de France (pp. 297-325 y 267-295).

Las dos tratan del positivismo. Para darlas, alega France que esta filosofía ha tenido un papel fundamental en la vida intelectual del Brasil, como lo atestigua el lema de su escudo nacional "Orden y progreso". Pero su objetivo verdadero, lo mismo que cuando escogió el tema de Rabelais, era sin duda animar allí los elementos de disolución social, sin atacar de frente las fuerzas de la tradición.

La conferencia sobre Comte contiene algunos párrafos elocuentes sobre el porvenir del Brasil como centro del mundo latino:

"Je comprends tous les sentiments qu'inspire à ses enfants, dans sa fédération glorieuse, la patria brésilienne" ( $p$. 290 ).

"L'axe du monde se déplace. Le vaste océan qui, si longtemps, sépara les peuples, maintenant les unit. La civilisation, la richesse, la puissance viennent régner sur votre terre écla- 
tante au regard de votre ciel tout vibrant des flèches du soleil. C'est là, dans un pays d'une incomparable splendeur, que par vous, Messieurs, par vous, libres sur une terre féconde et neuve, le génie latin réalisera les rêves les plus nobles et les plus beaux qu'aient jamais formés les sages de la vieille Europe notre mère. C'est là que se réalisera l'idéal de justice, d'intelligence, de bonté formé durant des siècles de souffrance et d'espoir par vos pères et les miens" (pp. 294-95).

¿Esto lo creía sinceramente Anatole France? Confieso que estas palabras me parecen palabras de orador, frases huecas. Huelen a hipocresía también por los elogios desmesurados que las acompañan, elogios de Machado de Assis, Ruiz Barbosa, José Verissimo y Rio-Branco.

Los intelectuales de la Argentina, el Uruguay y el Brasil se comieron tales frases como pan bendito. Véanse los periódicos latinoamericanos de aquel año para juzgar. Merece una nota especial el libro $A M$. Anatole France, Hommage de la jeunesse argentine (Buenos Aires: Imp. Kraft, 1909, p. 21) ; contiene discursos entusiastas de Ch. Ibarguren, Eug. Thiébault y Rob. Levillier.

¿Dónde está la verdad? ¿Anatole France, admiraba sinceramente a la América latina? ¿O era un hipócrita incomparable? Me inclino a esta última hipótesis. Un análisis detenido de la vida de A. France me hace pensar que en todo era un hipócrita, un actor cuyas palabras visionarias disfrazaban un fondo de desdén aristocrático. Confieso que tengo un prejuicio inicial: no me es simpática la raza de los literatos. iLiteratura!

$$
\begin{gathered}
\text { Ronald Hruton, } \\
\text { The University of British Columbia, } \\
\text { Vancouver, Canada. }
\end{gathered}
$$

(1).-Véase Maurice Gaffiot, Les Théories d'Anatole France sur l'organisation sociale de son temps (Paris: Rivière, 1928), ch. viii.

(2).-El Diario, 28 de abril, 1910, Le Courrier de la Plata, 29 de abril, 1910. 
